\title{
Rémi Fabre, Les Protestants en France depuis 1789
}

Paris, La Découverte 1999. 112 p. (bibliogr.) (coll. « Repères » $n_{0} 273$ )

Danièle Hervieu-Léger

\section{(2) OpenEdition}

1 Journals

Édition électronique

URL : http://journals.openedition.org/assr/453

DOI : $10.4000 /$ assr. 453

ISSN : $1777-5825$

Éditeur

Éditions de l'EHESS

\section{Édition imprimée}

Date de publication : 2 octobre 2001

Pagination : 93-156

ISBN : 2-222-96712-0

ISSN : 0335-5985

Référence électronique

Danièle Hervieu-Léger, «Rémi Fabre, Les Protestants en France depuis 1789 », Archives de sciences sociales des religions [En ligne], 116 | octobre - décembre 2001, document 116.17, mis en ligne le 21 novembre 2005, consulté le 24 septembre 2020. URL : http://journals.openedition.org/assr/453 ; DOI : https://doi.org/10.4000/assr.453 
gulation des relations au sein du groupe. En effet, le récit pose la question de la préservation du lignage et de l'exigence d'endogamie, dans l'Ancien Testament comme chez les chrétiens ; quant au choix libre et consenti du partenaire sexuel, il affirmerait la primauté de l'individu sur le groupe.

L'A. rejoint ici des observations de Weber. Si le respect de la Loi, le lignage ou la place du prophète travaillent et transforment le motif, n'est-ce pas parce que, d'une part « le judaïsme ne connaît comme voie de salut que la fidélité à la Loi » et que d'autre part «le prophète, le prêtre (..) dût être plus proche du croyant que ne l'étaient la parenté naturelle ou la communauté conjugale envisagées comme telles (...) et que la finalité du salut-délivrance [était] plus intériorisée. Tout en dévalorisant (...) ces relations, et en faisant éclater les liens magiques qui enferment les hommes dans la sphère exclusive de la parentèle, la prophétie créait une nouvelle communauté sociale, surtout là où elle devenait une religiosité sotériologique de groupement communautaire »?

Si les œuvres permettent de repérer les façons dont se disent ces réalités, des questions restent en suspens lorsqu'on referme l'ouvrage. Deux particulièrement interrogent le sociologue.

La lecture sémiotique proposée ici n'est-elle pas contrainte par l'histoire? Origène ou Ambroise sont des exceptions dans une société illettrée ; la décoration d'un cercueil en pierre ne signe-t-elle pas aussi un statut social valorisé ? Dès lors, de quelles réalités sociales s'agit-il, sinon celle, par exemple, du lignage d'individus dominants dans des sociétés hautement hiérarchisées auquel cas l'évolution du motif traduirait aussi l'évolution des rapports de pouvoir dans ces sociétés, chrétienne ou non chrétienne?

Par ailleurs, qu'en est-il de l'artiste? Luimême est pris dans des logiques sociales; elles le mettent peu à peu à distance des institutions qui disent la Loi, notamment la religion. Ainsi le renversement du motif, dans le Déjeuner sur l'herbe de Manet, judicieusement évoqué dans la conclusion, ne manifeste-t-il pas cette montée du statut de l'artiste moderne ? Cet avènement, ne change-t-il pas aussi le statut du motif?

La place de l'individu dans la société occidentale, l'inadéquation des normes anciennes véhiculées par le religieux, n'offrent-elles pas des pistes pour comprendre la disparition du motif? Le questionnement sociologique viendrait alors, non du motif, cette fois, mais de l'artiste et de sa place dans la société question- nant les œuvres par son œuvre. Le débat est ouvert.

Christian Vogels.

116.17

FABRE (Rémi).

Les Protestants en France depuis 1789. Paris, La Découverte 1999. 112 p. (bibliogr.) (coll. « Repères » $n^{\circ} 273$ ).

La collection « Repères »-dans laquelle $\mathrm{R}$. Azria nous a offert en 1996 une présentation remarquablement dense de l'histoire juive, de la période biblique à l'époque actuelle ( $L e$ Judaïsme, $\mathrm{n}^{\circ} 203$ [Arch. 98.5]) - a également introduit dans son catalogue deux ouvrages spécifiquement consacrés à l'histoire religieuse de la France contemporaine : l'un sur les catholiques depuis la Restauration ; l'autre sur les protestants depuis la Révolution. Le premier, paru en 1997, a déjà fait 1'objet d'une recension dans les Archives, sous la plume de Michel Lagrée (récemment disparu) (Arch. 104.49). Le second est sorti en 1999. On remarquera, d'entrée de jeu, la différence de point de départ temporel. Pour le catholicisme, la Restauration marque, après la rupture révolutionnaire, la politique de déchristianisation et les années de crise dramatique qui font suite à la promulgation de la Constitution Civile du Clergé, le moment d'une réorganisation, marquée en particulier par la restructuration du système paroissial. Mais cette réorganisation, rendue possible par le compromis concordataire, marque aussi l'entrée de la France dans un régime nouveau des rapports du religieux et du politique, qui fait du culte catholique un culte parmi d'autres. En marquant clairement la prééminence de la sphère politique sur la sphère religieuse, le Concordat contribue à assurer, sur un mode relativement pacifié, cette «sortie de la religion » qui correspond à l'entrée de la nation dans la modernité politique.

Le petit ouvrage de R.F. éclaire, de façon claire et précise, les dynamiques sociales, politiques et théologiques à travers lesquelles les protestants français vont s'ajuster et apporter leur contribution à la construction de cette modernité. Si 1789 constitue le point de départ du livre, c'est parce que la Révolution met fin, pour les communautés protestantes, à l'histoire dramatique de la persécution et qu'elle ouvre aux protestants, en les réintégrant dans la société française, l'accès à la citoyenneté. À partir de ce point de départ, l'auteur met en perspective le parcours par lequel une minorité religieuse - ancrée initialement dans des communautés rurales - est progressivement conduite à jouer, dans le procès de la construc- 
tion politique, économique et intellectuelle de la France moderne, un rôle considérable, sans rapport avec l'influence à laquelle peut statistiquement prétendre un groupe qui ne représente pas plus de $2 \%$ de la population française. Si le Concordat a servi à Napoléon à « corseter » le catholicisme, les articles organiques publiés le 8 avril 1802 font entrer les cultes réformés et luthériens dans une sécurité retrouvée, mais qui implique, pour les réformés, l'abandon du système presbytéro-synodal en vigueur depuis 1559. Le statut de germinal produit l'unification forcée des luthériens, mais il implique, pour les réformés, une mise sous tutelle administrative qui suscite leur méfiance. Le poids de cette tutelle étatique est cependant compensé, au sein de la nouvelle donne confessionnelle, par la mise au pas d'un catholicisme qui perd ainsi une grande partie des moyens de son écrasante domination. En même temps qu'il consacre le soutien des protestants au régime issu de la Révolution, le dispositif concordataire crée les conditions d'un véritable renouveau qui s'affirme nettement à partir de 1815 , sur le terrain spirituel et pastoral autant que sur le terrain théologique. Dans la France des révolutions, cassée en deux par l'affrontement du catholicisme intransigeant et des Républicains, le protestantisme français occupe une place marquante dans la vie sociale et politique. En même temps que s'affirme une bourgeoisie protestante activement engagée dans le développement industriel et financier de la nation, les protestants soutiennent indéfectiblement un projet libéral auquel ils apportent une contribution intellectuelle et pratique décisive. Cette influence culmine sous la III ${ }^{\mathrm{e}}$ République avec la confirmation de la présence notable des protestants dans tous les domaines de la vie publique, politique et administrative, et au cœur de l'appareil d'Etat, où ils jouent un rôle décisif dans la mise en place de la laïcité et de l'école républicaine. Le tournant historique auquel correspond la mise en place du régime de Séparation en 1905 suscite cependant un certain nombre de tensions et de divisions au sein d'un corps protestant que l'affaire Dreyfus et surtout la Guerre de 1914-1918 vont contribuer à rassembler. Le conflit mondial et la crise morale qui l'accompagne et le suit favorisent, autour de la figure majeure du théologien suisse Karl Barth, l'émergence d'une " théologie de temps de crise » qui triomphe dans l'Église réformée de France et même à l'échelle de l'ensemble du protestantisme au sortir de la Seconde Guerre mondiale. Les années soixante marquent la fin $\mathrm{du}$ monopole théologique du barthisme, en même temps qu'elles sont caractérisées par l'avancée remarquable d'une sensibilité œcuménique qu'entretiennent les mutations d'un catholicisme, lui-même pris dans l'aggiornamento conciliaire. La guerre d'Algérie, le rapprochement des Églises chrétiennes, les nouvelles formes de contestation sociale qui émergent à la fin des Golden sixties produisent une reconfiguration interne des différents courants du protestantisme français. Celui-ci s'interroge, non sans une certaine angoisse, sur sa place et son identité propre au sein d'une société définitivement séculière et moderne, qu'il a profondément contribué à modeler. Il est un peu dommage, de ce dernier point de vue, que le livre de R. F. présente de façon rapide et un peu plate la poussée récente des Églises évangéliques (au-delà de la Mission évangélique tsigane) et qu'il n'interroge pas davantage la signification de la diffusion d'une sensibilité évangélique en dehors même de ces Églises. Mais il faut saluer, en tout état de cause, l'utilité de la mise en place et de la synthèse qu'il propose, s'agissant d'une histoire difficile d'accès au non spécialiste.

Danièle Hervieu-Léger.

116.18

FAINZANG (Sylvie).

Médicaments et Société. Le patient, le médecin, et l'ordonnance. Paris, Presses Universitaires de France, 2001, 156 p. (bibliogr.) (coll. « Ethnologies-Controverses »).

Parmi les études relatives aux comportements de santé la question du respect de l'ordonnance médicale a donné lieu à des analyses sociologiques sur les diverses attitudes des patients à l'égard de la prescription médicale. Dans cette perspective de recherche, S.F., en tant qu'anthropologue, s'interroge sur la manière dont des patients et leurs familles gèrent les médicaments prescrits par leur médecin, et aussi sur les rapports que tous entretiennent avec ce dernier, plus largement encore avec l'autorité médicale. En effet, l'auteur pose la question de la longévité d'une ordonnance médicale, et de l'importance que les individus accordent à la matérialité de " la chose écrite ». Mais la question essentielle porte sur les dimensions susceptibles de faire varier les attitudes des patients à l'égard de la coopération avec les médecins parmi lesquelles elle retient l'origine religieuse.

L'ouvrage s'ouvre sur les thématiques du patient et de son rapport au suivi de l'ordonnance, aux médicaments, à son corps et aux médecins. L'analyse repose sur un travail comparatif, fondé sur l'observation et la participation, mené par l'A. durant cinq ans dans les régions du Gard et de l'Hérault auprès de populations rurale et urbaine. Celles-ci sont compo- 